\title{
Estimation of Production Forgone
}

\author{
A. L. JENSEN \\ School of Natural Resources, University of Michigan \\ Ann Arbor, Michigan 48109, USA \\ R. H. Reider AND W. P. Kovalak \\ Engineering Research, Detroit Edison Company \\ Detroit, Michigan 48226, USA
}

\begin{abstract}
Three methods for estimating production forgone were compared by assessing the effects of power plant entrainment and impingement on gizzard shad Dorosoma cepedianum in western Lake Erie. The three approaches evaluated were (1) the Rago (1984) method, which is a direct method based on exponential mortality and growth, (2) a continuous-time direct method based on exponential mortality and the von Bertalanffy growth equation, and (3) an indirect method, based on exponential mortality and the von Bertalanffy growth equation, in which production forgone was calculated as the difference between population production with and without an environmental disturbance. The indirect method gives a measure of the relative effect of the power plant-induced mortality and production, but requires estimation of recruitment, which is difficult to estimate. An initial estimate of production forgone by the direct approach of Rago (1984), which does not require an estimate of recruitment, can be used to estimate recruitment for the indirect estimate of production forgone; together, the direct and indirect approaches give a more complete assessment of production forgone. A sensitivity analysis showed production forgone was sensitive to changes in mortality rates of larvae, young of the year, and juveniles and to change in the asymptotic weight of adults.
\end{abstract}

Production is the body mass produced by a population during some period of time, and includes mass lost through mortality (Ricker 1946). Production forgone is the biomass that would have been produced by fish killed by an environmental disturbance, such as a power plant might induce, if they had not been killed and had been subject to the same growth and mortality as fish not killed (Rago 1984). The direct method for calculation of production forgone suggested by Rago (1984) has several advantages over other methods; most important is that population production need not be estimated to calculate production forgone. Numbers of fish killed are used as initial values in the equations for production; the mortality and growth coefficients in the production equations are the same as those for the population. In indirect methods, production forgone is calculated as the difference between production of the population with and without an environmental disturbance.

The Rago (1984) model for production forgone is based on Ricker's $(1946,1975)$ production model. This approach is conceptually simple, but requires estimation of many population parameters, assumes exponential growth, and does not allow a sensitivity analysis of growth parameters usually applied for assessment of fisheries. In this study a direct method for calculation of production for- gone is developed from the same models for growth and mortality that were used in the Beverton and Holt (1957) analytical yield equation. This approach gives a continuous-time model.

An important disadvantage of using direct methods for estimation of production forgone is that the relative severity of an environmental disturbance is not determined. Production forgone may seem large but, when compared to production of the surviving population, it may be insignificant. Therefore, as a third approach, production forgone was calculated indirectly by taking the difference between production of a population with and without the environmental disturbance. Recruitment was estimated by adjusting recruitment until production forgone calculated with the indirect method approximated production forgone calculated with the direct method. This does not give two independent estimates of production forgone, but it does give a measure of the relative effect.

\section{Development of Models for Production Forgone}

\section{Rago Model}

Biomass $(B)$ of a population is related to numbers $(N)$ and average individual weight $(W)$ by

$$
B=N W \text {, }
$$


and the change in biomass of a population with respect to age $(x)$ can be described by

$$
d B / d x=W(d N / d x)+N(d W / d x) .
$$

Equation (2) gives change in biomass as the sum of the initial biomass lost through mortality and the production of new biomass through growth; the second term is the rate $(d P / d x)$ of biological production $(P)$ (Ricker 1946). Production over some period of time $\Delta x$, such as a year, is

$$
P=\int_{\Delta x} N(d W / d x) d x .
$$

Equation (3) can be applied to calculate the production of a cohort over any length of time. In a steady state, production of a cohort over its life span equals annual production of a population (Beverton and Holt 1957).

To estimate production forgone, one starts at the time of the disturbance-related mortality and computes lost production of fish that were killed. The rate of production of age group $i$ is given by

$$
d P_{i} / d x=N_{i} d W_{i} / d x .
$$

Rago (1984) described mortality and growth using the simple exponential equations

$$
N_{x}=N_{i} \exp \left[-Z_{i}(x-i)\right]
$$

and

$$
W_{x}=W_{i} \exp \left[G_{i}(x-i)\right]
$$

that were used by Ricker (1946) in his original formulation of production; $N_{i}$ is the number of individuals of age $i$ killed, $W_{i}$ is the weight of age- $i$ individuals, $N_{x}$ is the number of individuals of age $x, W_{x}$ is the weight of an individual of age $x, Z_{i}$ is the total instantaneous mortality coefficient for individuals of age $i$, and $G_{i}$ is the growth coefficient for individuals of age $i$. Combining the above equations and solving from $x=i$ to $x=i+\Delta x$ gives

$$
P_{i}=G_{i} N_{i} W_{i} \frac{\exp \left[\left(G_{i}-Z_{i}\right) \Delta x\right]}{G_{i}-Z_{i}},
$$

and production from some interval $j$ onwards throughout the life span is

$$
P_{j}=\sum_{i=j}^{p} G_{i} N_{i} W_{i} \frac{\exp \left[\left(G_{i}-Z_{i}\right) \Delta x\right]}{G_{i}-Z_{i}},
$$

$v$ being the maximum age attainable.

\section{Analytical Model}

To develop the production model based on the growth and mortality equations of the Beverton and Holt (1957) model, the life span of a fish was separated into four stages: larvae, young of the year (age 0), juvenile, and adult. The following ages were used:

$$
\begin{aligned}
x_{0} & =\text { time when eggs hatch; } \\
\mathrm{DL} & =\text { duration of larval stage; } \\
x_{L} & =\text { time when age- } 0 \text { fish become } 1 \text { year old; } \\
x_{R} & =\text { age at maturity; } \\
v & =\text { oldest age attainable. }
\end{aligned}
$$

The equations for production, mortality, and weight are

$$
\begin{aligned}
& d P / d x= N(d W / d x) \\
& d N / d x=-M_{1} N, \text { for larvae; } \\
& d N / d x=-M_{2} N \\
& \text { for } x_{0}<x<x_{L} \\
& d N / d x=-M_{3} N \\
& \text { for } x_{L}<x<x_{R} \\
& d N / d x=-\left(M_{4}+F\right) N \\
& \quad \text { for } x>x_{R} ; \\
& d W / d x=3 W_{\text {inf } K} K \exp \left[-K\left(x-x_{0}-\mathrm{DL}\right)\right] \\
& \cdot\left\{1-\exp \left[-K\left(x-x_{0}-\mathrm{DL}\right)\right]\right\}^{2}
\end{aligned}
$$

$K$ is the growth coefficient, $W_{\text {inf }}$ is the asymptotic weight, $M_{1}, M_{2}, M_{3}$, and $M_{4}$ are instantaneous natural mortality coefficients for larvae, age- 0 fish, juveniles, and adults, respectively, and $F$ is the instantaneous fishing mortality coefficient. The equations for calculation of production for each life stage are

$$
\begin{aligned}
P_{\text {larvac }}= & \int_{\mathrm{DL}} N(d W / d x) d x \\
& +\int_{x_{0}}^{x_{L}} N(d W / d x) d x \\
& +\int_{x_{L}}^{x_{R}} N(d W / d x) d x \\
& +\int_{x_{R}}^{v} N(d W / d x) d x \\
P_{\mathrm{agc} 0}= & \int_{x_{0}}^{x_{L}} N(d W / d x) d x \\
& +\int_{x_{L}}^{v} N(d W / d x) d x \\
& +\int_{x_{R}}^{v} N(d W / d x) d x ;
\end{aligned}
$$




$$
\begin{aligned}
P_{\text {juvenile }}= & \int_{x_{L}}^{x_{R}} N(d W / d x) d x \\
& +\int_{x_{R}}^{v} N(d W / d x) d x \\
P_{\text {adults }}= & \int_{x_{R}}^{v} N(d W / d x) d x .
\end{aligned}
$$

The solutions for the above equations are listed in Appendix 1. If the numbers of fish killed are used as initial values in the above equations for production, the equations become equations for calculation of production forgone.

\section{Indirect Method}

The effect of a disturbance on biomass, yield, and production of a population can be treated with a model similar to the one that Beverton and Holt (1957) applied to assess yield. In this approach, the entire population is modeled rather than just the "shadow" cohort, which consists of those individuals entrained or impinged. Terms describing power plant entrainment and impingement are included in the model, which consists of the following equations:

$$
\begin{aligned}
d P / d x= & N(d W / d x) \\
d Y / d x= & F N W, \text { for } x>x_{R} ; \\
d N / d x= & -\left(M_{1}+h Q\right) N, \text { for larvae; } \\
d N / d x= & -\left(M_{2}+f Q\right) N, \\
& \text { for } x_{0}<x<x_{L} ; \\
d N / d x= & -\left(M_{3}+f Q\right) N \\
& \text { for } x_{L}<x<x_{R} ; \\
d N / d x= & -\left(M_{4}+f Q+F\right) N, \\
& \text { for } x>x_{R} ; \\
d W / d x=3 W_{\text {in } K} K \exp \left[-K\left(x-x_{0}-\mathrm{DL}\right)\right] & \cdot\left\{1-\exp \left[-k\left(x-x_{0}-\mathrm{DL}\right)\right]\right\}
\end{aligned}
$$

The new terms in the above equations are yield $Y$, the entrainment coefficient $h$, the impingement coefficient $f$, and the annual water discharge of the power plant $Q$. As above, the lifespan was separated into four stages and the solution was obtained for biomass, yield, and production (Appendices 2 and 3 ).

\section{Application to Gizzard Shad}

The three different approaches for estimating production forgone were applied to estimate the impact resulting from entrainment and impingement of gizzard shad Dorosoma cepedianum at the Monroe Power Plant, Monroe, Michigan, on the western shore of Lake Erie.

\section{Rago Model}

Data for estimation of parameters were obtained from Bodola (1966), Lawler, Matusky \& Skelly Engineers (LMS 1980), and Ohio Department of Natural Resources (ODNR 1985); the parameter estimates are listed in Table 1. Estimates of length at age data (Bodola 1966) were applied to estimate the annual growth rates for ages greater than 0 . To calculate the mean weight of larvae, a total length $(L)$ of $5 \mathrm{~mm}$ was assumed (Jude et al. 1983), and then the length-weight relation (Bodola 1966)

$$
W=5.1729 \times 10^{-6} L^{3.12}
$$

was applied to calculate weight. The estimated average weight of entrained larvae was $0.00078 \mathrm{~g}$. The larval growth coefficient $(g)$ was estimated as 14.07 per year from

$$
g=\log _{e}[W(x+1) / W(x)] / \mathrm{DL} ;
$$

weight at the end of the larval stage was calculated with the von Bertalanffy equation for growth in weight. To estimate the larval mortality coeffcient, it was assumed that the net reproductive rate was one, and the equation for the net reproductive rate given by Jensen (1985) was applied. Mortality coefficients for other life stages were estimated with abundance data reported by LMS (1980) and the equation

$$
Z=\log _{e}[N(x) / N(x+1)] \text {. }
$$

Total production forgone for gizzard shad estimated by Rago's (1984) method was $5.51 \times 10^{5}$ $\mathrm{kg}$ (Table 1). A large portion of the production forgone was due to entrainment of larvae and impingement of age- 0 gizzard shad. Total production forgone appears large, but the severity of impact is difficult to judge without some knowledge of gizzard shad production in the western basin of Lake Erie.

\section{Analytical Model}

The ages used to separate the life span into four intervals were

$$
\begin{aligned}
x_{0}= & \text { time of year when eggs hatch }=0.5 \text { years; } \\
\mathrm{DL}= & \text { duration of larval stage }=0.1 \text { years; } \\
x_{L}= & \text { time when age- } 0 \text { fish become age } 1=1 \\
& \text { year; }
\end{aligned}
$$


TABLE 1. - Parameter estimates and production forgone generated by the Rago model for gizzard shad vulnerable to a Lake Erie power plant. $G$ and $M$ are instantaneous rates of growth and natural mortality, respectively.

\begin{tabular}{cccccc}
\hline Age & Number killed & Mean weight (g) & $G$ & $M$ & $\begin{array}{c}\text { Production forgone } \\
\text { (kg/year) }\end{array}$ \\
\hline Larvae & $4 \times 10^{9}$ & 0.00078 & 14.07 & 50.42 & $2.36 \times 10^{5}$ \\
0 & $2.88 \times 10^{7}$ & 1.02 & 2.35 & 2.86 & $2.62 \times 10^{5}$ \\
1 & $7.90 \times 10^{5}$ & 49 & 1.12 & 2.89 & $2.23 \times 10^{4}$ \\
2 & $5.25 \times 10^{4}$ & 150 & 1.52 & 2.64 & $7.26 \times 10^{3}$ \\
3 & $4.15 \times 10^{4}$ & 687 & 0.22 & 1.97 & $3.34 \times 10^{3}$ \\
4 & $5.14 \times 10^{4}$ & 854 & 0.12 & 1.77 & $4.16 \times 10^{3}$ \\
5 & $4.01 \times 10^{4}$ & 962 & 0.14 & 0.60 & $8.20 \times 10^{3}$ \\
6 & $2.26 \times 10^{4}$ & 931 & 0.16 & 0.60 & $3.83 \times 10^{3}$ \\
7 & $1.35 \times 10^{4}$ & 1,092 & 0.08 & 0.60 & $1.42 \times 10^{3}$ \\
8 & $1.76 \times 10^{4}$ & 1,183 & 0.08 & 0.62 & $1.30 \times 10^{3}$ \\
Total & & & & & $5.51 \times 10^{5}$ \\
\hline
\end{tabular}

$$
\begin{aligned}
x_{R} & =\text { age at recruitment }=3 \text { years; } \\
v & =\text { oldest age attainable }=7 \text { years. }
\end{aligned}
$$

These parameters were estimated with data from Bodola (1966), LMS (1980), and ODNR (1985). Larval, age- 0 , and juvenile mortalities were estimated with the approach applied for the Rago method above; for adult mortalities, regression (Ricker 1975) was applied to data reported by LMS (1980). Estimated instantaneous mortality coefficients were 50.42 for larvae, 2.86 for age-0 fish, 2.71 for juveniles, and 1.72 for adults. The growth equation

$$
L=L_{\text {inf }}\left(1-e^{-K x}\right)
$$

was fitted by the method described by Gulland (1969); $L_{\text {in }}$ is the asymptotic length and $K$ is the growth coefficient. The estimated asymptotic length was $500 \mathrm{~mm}$ and, from the length-weight regression, the estimated asymptotic weight was 1,363 g. The estimated growth coefficient $(K)$ was 0.42 per year, and the exponent of the length-weight relation (b) was 3.12 .

Total production forgone for gizzard shad estimated by the analytical method was $5.89 \times 10^{5}$ $\mathrm{kg}$ (Table 2). As with the Rago model, most of the production forgone was due to entrainment of larvae and impingement of age- 0 fish.

\section{Indirect Method}

For indirect estimation of production forgone, the additional parameters necessary were the number of eggs per unit of female biomass, the proportion of females in the mature stock, proportion of eggs that hatch, number of recruits, and annual water discharge at the power plant. All of these parameters except recruitment and water discharge were estimated from data given by Bodola (1966), LMS (1980), and ODNR (1985). The parameter estimates were: number of eggs per gram of female, 529; proportion of eggs that hatch, 0.75 ; and proportion females, 0.68 . Annual discharge was estimated by Jude et al. (1983) as $1.9 \times 10^{9}$ $\mathrm{m}^{3}$. Recruitment was estimated by adjusting recruitment so that production forgone calculated by the direct method approximated production forgone calculated by the indirect method. Estimates of production forgone calculated by the direct and indirect methods are not independent, but application of the indirect method gives a measure of the relative effects of entrainment and impingement. Fishing mortality was estimated by adjusting it so that calculated yields approximated observed yields; total mortality was held constant. A fishing mortality of 0.80 and natural mortality of 0.92 maintained the total mortality of adults at 1.72 and the calculated yields were close to the observed yields. Entrainment and impingement coefficients were estimated as $h=1.35 \times 10^{-11}$, year and $f=3.20 \times 10^{-11 / y e a r}$ with the method described by Jensen and Hamilton (1982).

The estimated annual production of the gizzard shad population in the absence of power plant-

TABLE 2.-Estimates of production forgone generated by the analytical model for gizzard shad vulnerable to a Lake Erie power plant.

\begin{tabular}{cc}
\hline Age & Production forgone (kg/year) \\
\hline Larvae & $2.56 \times 10^{5}$ \\
0 & $2.84 \times 10^{5}$ \\
1 & $2.67 \times 10^{4}$ \\
2 & $4.38 \times 10^{3}$ \\
3 & $5.90 \times 10^{3}$ \\
4 & $6.33 \times 10^{3}$ \\
5 & $3.81 \times 10^{3}$ \\
6 & $1.54 \times 10^{3}$ \\
7 & $5.74 \times 10^{2}$ \\
Total & $5.89 \times 10^{5}$ \\
\hline
\end{tabular}


induced mortality was 9,959 tonnes; with the additional mortality it was 9,389 tonnes (Table 3). The difference between these values, $5.7 \times 10^{5} \mathrm{~kg}$, is the estimated annual production forgone.

\section{Discussion}

There is a high degree of uncertainty in estimation of production forgone because there is a high degree of uncertainty in estimation of some model parameters. This uncertainty results both from the difficulty of sampling fish populations, and from the large annual variation in recruitment, growth, and mortality in Lake Erie fish populations (ODNR 1985). Although many parameters must be estimated to compute production forgone, errors in estimation of several parameters have only a small effect on the estimate of production forgone. Changes in adult mortality, initial larval size, and larval growth rate have little effect on production forgone; change in the asymptotic weight of adults has a large influence on production forgone; the maximum weight attained is linearly related to production forgone (Figure 1). Asymptotic weight can usually be estimated accurately. Although adult mortality has little effect on production forgone, mortality of age- 0 fish and of juveniles (Figure 2) can have large effects. As indicated by Rago (1984), larval mortality, which has a severe effect (Figure 2), is difficult to estimate.

Although application of the indirect method does not give an independent estimate of production forgone, it gives a measure of the relative effect. Production forgone is very large in the gizzard shad cases examined, but the decrease in production of the population is only $6 \%$. The effect on biomass is much greater than that on production, and the effect on yield is somewhat higher than that on biomass. Applying a surplus production

TABLE 3.-Biomass, yield, production, and production forgone estimated by the indirect method for a gizzard shad population with and without mortality due to power plant entrainment and impingement.

\begin{tabular}{|c|c|c|c|}
\hline Parameter & $\begin{array}{l}\text { With power } \\
\text { plant } \\
\text { mortality }\end{array}$ & $\begin{array}{l}\text { Without } \\
\text { power } \\
\text { plant } \\
\text { mortality }\end{array}$ & Ratio \\
\hline $\begin{array}{l}\text { Biomass (kg) } \\
\text { Yield (kg/year) }\end{array}$ & $\begin{array}{r}3,330 \times 10^{3} \\
558 \times 10^{3}\end{array}$ & $\begin{array}{r}3,880 \times 10^{3} \\
672 \times 10^{3}\end{array}$ & $\begin{array}{l}0.86 \\
0.83\end{array}$ \\
\hline $\begin{array}{l}\text { Production } \\
\text { (kg/year) } \\
\text { Production forgone } \\
\text { (kg/year) }\end{array}$ & $\begin{array}{r}9,389 \times 10^{3} \\
5.70 \times 10^{5}\end{array}$ & $9,959 \times 10^{3}$ & 0.94 \\
\hline
\end{tabular}

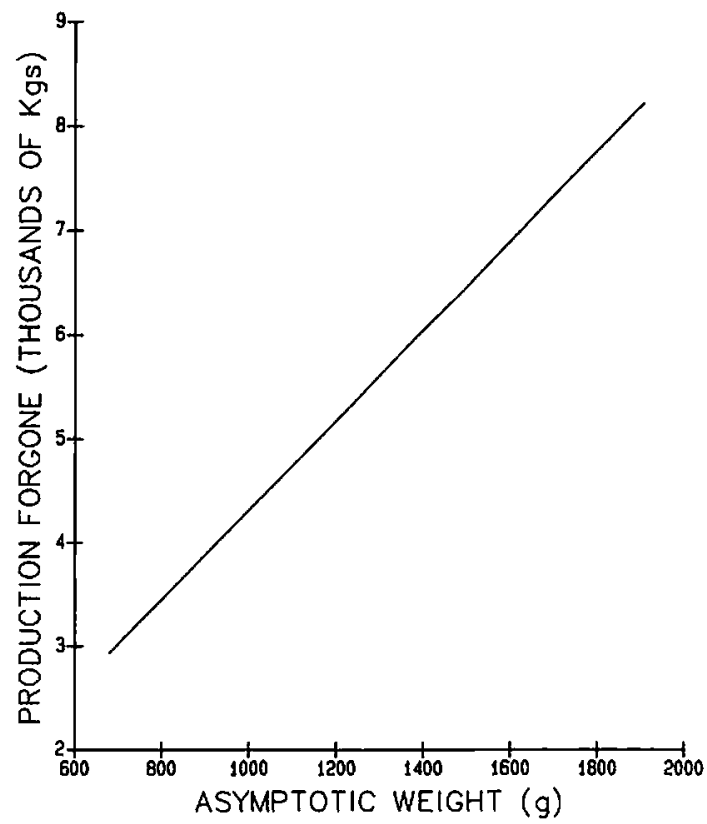

FIGURE 1.- Relation between production forgone, calculated by the direct method with the analytical model, and maximum weight (asymptotic weight) for gizzard shad.
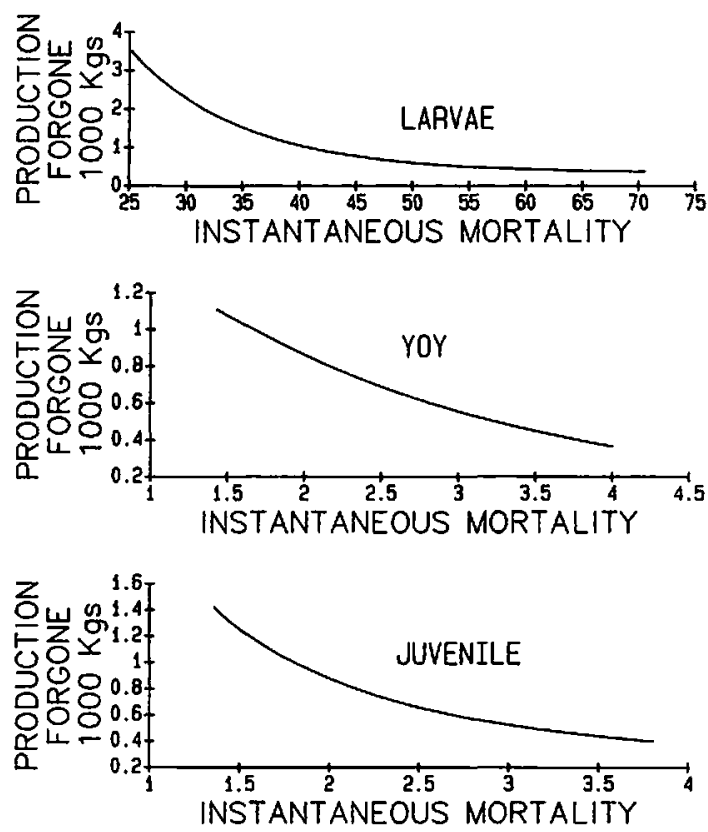

FIGURE 2. - Relation between production forgone, calculated by the direct method with the analytical model, and mortality rates for larval, young-of-the-year (YOY), and juvenile gizzard shad. 
model, Jensen (1982) showed that the effect of entrainment and impingement would be larger on yield than on biomass. The effect on yield would be important if gizzard shad supported a valued commercial or sport fishery. Yield to the gizzard shad fishery was estimated as $556,976 \mathrm{~kg}$ with the population model, and the reported yields for the Michigan waters of the western Lake Erie basin were $297,101 \mathrm{~kg}$ in 1983 and $573,882 \mathrm{~kg}$ in 1984 (A. Frank, U.S. Fish and Wildlife Service, personal communication).

Combining Rago's (1984) direct estimate of production forgone with the indirect estimate enables estimation of both production forgone and the relative effect of this loss on the population.

\section{References}

Beverton, R. J. H., and S. J. Holt. 1957. On the dynamics of exploited fish populations. Fishery Investigations, Series II, Marine Fisheries, Great Britain Ministry of Agricuture Fisheries and Food 19.

Bodola, A. 1966. Life history of the gizzard shad, Dorosoma cepedianum (LeSueur) in western Lake Erie. U.S. Fish and Wildlife Service Fishery Bulletin 65: $391-425$.

Gulland, J. A. 1969. Manual of methods for fish stock assessment. Part 1. Fish population analysis. FAO (Food and Agriculture Organization of the United Nations) Manuals in Fisheries Science 4.

Jensen, A. L. 1982. Impact of a once through cooling system on the yellow perch stock in the western basin of Lake Erie. International Journal for Ecological Modelling 15:127-144.

Jensen, A. L. 1985. Relations among net reproductive rate and life history parameters for lake whitefish (Coregonus clupeaformis). Canadian Journal of Fisheries and Aquatic Sciences 42:164-168.

Jensen, A. L., and T. A. Hamilton. 1982. Application of a conventional fishery model for assessment of entrainment and impingement impact. Environmental Biology of Fishes 7:181-185.

Jude, D. J., P. J. Mansfield, and M. Perrone, Jr. 1983. Impingement and entrainment of fish and effectiveness of the fish return system at the Monroe Power Plant, western Lake Erie, 1982-1983. University of Michigan, Great Lakes Research Division, Special Report 101, Ann Arbor.

LMS (Lawler, Matusky \& Skelly Engineers). 1980. Assessment of impingement and entrainment of selected fish species at the J. R. Whiting power plant. Report to Consumers Power Company, Jackson, Michigan.

ODNR (Ohio Department of Natural Resources). 1985. Status and trend highlights for Ohio's Lake Erie fish and fisheries. ODNR, Lake Erie Fisheries Unit Staff, Columbus.

Rago, P. J. 1984. Production forgone: an alternative method for assessing the consequences of fish entrainment and impingement at power plants and other water intakes. Ecological Modelling 24:79111.

Ricker, W. E. 1946. Production and utilization of fish populations. Ecological Monographs 16:374-391.

Ricker, W. E. 1975. Computation and interpretation of biological statistics of fish populations. Fisheries Research Board of Canada Bulletin 191.

\section{Appendix 1: Equations for Calculation of Production Forgone Based on the Analytical Model}

Production forgone of larvae is given by

$$
\begin{gathered}
P_{\text {larvac }}=\frac{g L W_{0}}{M_{1}-g} 1-\exp \left[-\left(M_{1}-g\right) \mathrm{DL}\right] \\
\times 3 K W_{\mathrm{ins}} L \exp \left[-M_{1} \mathrm{DL}-M_{2}\left(x_{L}-x_{0}\right)\right] \sum_{i=1}^{3} \frac{V_{i} \exp \left[-i K\left(x_{L}-x_{0}-\mathrm{DL}\right)\right]}{M_{2}+i K} \\
-3 K W_{\mathrm{inf}} L \exp \left(-M_{1} \mathrm{DL}\right) \sum_{i=1}^{3} \frac{V_{i} \exp (i K \mathrm{DL})}{M_{2}+i K} \\
-3 K W_{\mathrm{in} I} L \exp \left[-M_{1} \mathrm{DL}-M_{2}\left(x_{L}-x_{0}\right)\right] \sum_{i=1}^{3} \frac{V_{i} \exp \left[-i K\left(x_{R}-x_{0}-\mathrm{DL}\right)\right]}{M_{3}+i K} \\
+3 K W_{\mathrm{inf}} L \exp \left[-M_{1} \mathrm{DL}-M_{2}\left(x_{L}-x_{0}\right)-M_{3}\left(x_{R}-x_{L}\right)\right] \sum_{i=1}^{3} \frac{V_{i} \exp \left[-i K\left(x_{R}-x_{0}-\mathrm{DL}\right)\right]}{M_{3}+i K} \\
-3 K W_{\mathrm{ins}} L \exp \left[-M_{1} \mathrm{DL}-M_{2}\left(x_{L}-x_{0}\right)-M_{3}\left(x_{R}-x_{L}\right)\right. \\
\left.-\left(M_{4}+F\right)\left(x_{V}-x_{R}\right)\right] \sum_{i=1}^{3} \frac{V_{i} \exp \left[-i K\left(x_{R}-x_{0}-\mathrm{DL}\right)\right]}{M_{4}+F+i K}
\end{gathered}
$$


$+3 K W_{\text {inf }} L \exp \left[-M_{1} \mathrm{DL}-M_{2}\left(x_{L}-x_{0}\right)-M_{3}\left(x_{R}-x_{L}\right)\right.$

$$
\left.-\left(M_{4}+F\right)\left(x_{V}-x_{R}\right)\right] \sum_{i=1}^{3} \frac{V_{i} \exp \left[-i K\left(x_{V}-x_{0}-\mathrm{DL}\right)\right]}{M_{4}+F+i K}
$$

$V_{1}=-1, V_{2}=2$, and $V_{3}=-1$. In the above equation line (L1) gives production by larvae that would have occurred in the absence of entrainment. Lines (L2) and (L3) give production of age- 0 hish that would have resulted from entrained larvae. Lines (L4) and (L5) give production of juveniles that would have resulted from entrained larvae. Lines (L6) and (L7) give production of adults that would have resulted from entrained larvae. Equations for production forgone of young of the year, juveniles, and adults are obtained as follows. For age- 0 production forgone, use lines (L2)-(L7) and replace the number of larvae and the terms for their survival to young of the year in each line with the number of age- 0 fish impinged. For juvenile production forgone, use lines (L4)-(L7) and replace the number of larvae and the terms for their survival to the juvenile stage in each line with the number of juveniles impinged. For adult production forgone, use lines (L6) and (L7) and replace the number of larvae and the terms for their survival to adults in both lines with the number of adults impinged.

Appendix 2: Equation for Calculation of Biomass Based on the Analytical Model

$$
\begin{aligned}
B= & \frac{L W_{0}}{M_{1}+h Q-g}\left[1-\exp \left(-M_{i} \mathrm{DL}-h Q \mathrm{DL}+g \mathrm{DL}\right)\right] \\
& +L W_{\mathrm{inr}} \exp \left[-\left(M_{1}+h Q\right) \mathrm{DL}\right] \sum_{i=0}^{3} \frac{U_{i} \exp (i K \mathrm{DL})}{M_{2}+f Q+i K} \\
& -L W_{\mathrm{inr}} \exp \left[-\left(M_{1}+h Q\right) \mathrm{DL}-\left(M_{2}+f Q\right)\left(x_{L}-x_{0}\right)\right] \sum_{i=0}^{3} \frac{U_{i} \exp \left[-i K\left(x_{L}-x_{0}-\mathrm{DL}\right)\right]}{M_{2}+f Q+i K} \\
& +L W_{\mathrm{inf}} \exp \left[-\left(M_{1}+h Q\right) \mathrm{DL}-\left(M_{2}+f Q\right)\left(x_{L}-x_{0}\right)\right] \sum_{i=0}^{3} \frac{U_{i} \exp \left[-i K\left(x_{L}-x_{0}-\mathrm{DL}\right)\right]}{M_{3}+f Q+i K} \\
& -L W_{\mathrm{inr}} \exp \left[-\left(M_{1}+h Q\right) \mathrm{DL}-\left(M_{2}+f Q\right)\left(x_{L}-x_{0}\right)-\left(M_{3}+f Q\right)\left(x_{R}-x_{L}\right)\right] \\
& \cdot \sum_{i=0}^{3} \frac{U_{i} \exp \left[-i K\left(x_{L}-x_{0}-\mathrm{DL}\right)\right]}{M_{3}+f Q+i K} \\
& +L W_{\mathrm{inf}} \exp \left[-\left(M_{1}+h Q\right) \mathrm{DL}-\left(M_{2}+f Q\right)\left(x_{L}-x_{0}\right)-\left(M_{3}+f Q\right)\left(x_{R}-x_{L}\right)\right] \\
& \cdot \sum_{i=0}^{3} \frac{U_{i} \exp \left[-i K\left(x_{R}-x_{0}-\mathrm{DL}\right)\right]}{M_{4}+f Q+F+i K} \\
& -L W_{\mathrm{inr}} \exp \left[-\left(M_{1}+h Q\right) \mathrm{DL}-\left(M_{2}+f Q\right)\left(x_{L}-x_{0}\right)-\left(M_{3}+f Q\right)\left(x_{R}-x_{L}\right)\right. \\
& \left.-\left(M_{4}+f Q+F\right)\left(x_{V}-x_{R}\right)\right] \sum_{i=0}^{3} \frac{U_{i} \exp \left[-i K\left(x_{V}-x_{0}-\mathrm{DL}\right)\right]}{M_{4}+f Q+F+i K} \\
U_{0}= & -1, U_{1}=3, U_{2}=-3, \text { and } U_{3}=1 .
\end{aligned}
$$


Appendix 3: Equation for Calculation of Production for a Population

$$
\begin{aligned}
P= & \frac{g L W_{0}}{M_{1}+h Q-g}\left\{1-\exp \left[-\left(M_{1}+h Q-g\right) \mathrm{DL}\right]\right\} \\
& +3 K W_{\mathrm{inf}} L \exp \left[-\left(M_{1}+h Q\right) \mathrm{DL}-\left(M_{2}+f Q\right)\left(x_{L}-x_{0}\right)\right] \\
& \cdot \sum_{i=1}^{3} \frac{V_{i} \exp \left[-i K\left(x_{L}-x_{0}-\mathrm{DL}\right)\right]}{M_{2}+f Q+i K} \\
& -3 K W_{\mathrm{inf}} L \exp \left[-\left(M_{1}+h Q\right) \mathrm{DL}\right] \sum_{i=1}^{3} \frac{V_{i} \exp (i K \mathrm{DL})}{M_{2}+f Q+i K} \\
& -3 K W_{\mathrm{inf}} L \exp \left[-\left(M_{1}+h Q\right) \mathrm{DL}-\left(M_{2}+f Q\right)\left(x_{L}-x_{0}\right)\right] \\
& \cdot \sum_{i=1}^{3} \frac{V_{1} \exp \left[-i K\left(x_{L}-x_{0}-\mathrm{DL}\right)\right]}{M_{3}+f Q+i K} \\
& +3 K W_{\mathrm{inf} L} \exp \left[-\left(M_{1}+h Q\right) \mathrm{DL}-\left(M_{2}+f Q\right)\left(x_{L}-x_{0}\right)-\left(M_{3}+f Q\right)\left(x_{R}-x_{L}\right)\right] \\
& \cdot \sum_{i=1}^{3} \frac{V_{i} \exp \left[-i K\left(x_{R}-x_{0}-\mathrm{DL}\right)\right]}{M_{3}+f Q+i K} \\
& -3 K W_{\mathrm{inf}} L \exp \left[-\left(M_{1}+h Q\right) \mathrm{DL}-\left(M_{2}+f Q\right)\left(x_{L}-x_{0}\right)-\left(M_{3}+f Q\right)\left(x_{R}-x_{L}\right)\right] \\
& \cdot \sum_{i=1}^{3} \frac{V_{i} \exp \left[-i K\left(x_{R}-x_{0}-\mathrm{DL}\right)\right]}{M_{4}+f Q+F+i K} \\
& +3 K W_{\mathrm{inf} L} \exp \left[-\left(M_{1}+h Q\right) \mathrm{DL}-\left(M_{2}+f Q\right)\left(x_{L}-x_{0}\right)-\left(M_{3}+f Q\right)\left(x_{R}-x_{L}\right)\right. \\
& \left.-\left(M_{4}+f Q+F\right)\left(x_{V}-x_{R}\right)\right] \sum_{i=1}^{3} \frac{V_{i} \exp \left[-i K\left(x_{V}-x_{0}-\mathrm{DL}\right)\right]}{M_{4}+f Q+F+i K} .
\end{aligned}
$$

